Military Technical College Kobry El-Kobbah, Cairo, Egypt.

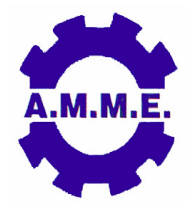

$15^{\text {th }}$ International Conference on Applied Mechanics and Mechanical Engineering.

\title{
CONSTRUCTIVE OPTIMIZATION OF TELESCOPIC PLATFORMS DUE TO VIBRATION
}

\author{
A. Yucel ${ }^{1}$ and A. Arpaci ${ }^{2}$
}

\begin{abstract}
In this study, vibrational analyses of telescopic platforms which are widely used in construction areas have been conducted and these structures have been optimized in order to satisfy vibrational standards. A vibration analysis has been conducted on a platform using solid modeling and finite element analysis method. Also the results of this analyses have been verified using experimental modal analyses. By means of finite element and experimental modal analyses, free vibration analyses have been implemented and natural frequencies and mode shapes have been determined. Also vibration acceleration values on the structure have been obtained by a forced vibration analysis conducted over the model. All these analyses have been done on the new optimized structure and it has been determined whether the optimized structure satisfies the vibrational standards.
\end{abstract}

\section{KEY WORDS}

Telescopic Platforms, Modal Analysis, Finite Element Method.

\footnotetext{
${ }^{1}$ (Corresponding Author) Dr. Lecturer, Istanbul Technical University, Mechanical Engineering Dept., Gumussuyu Istanbul Turkey, Tel: +902122931300 (Ext: 2404), e-mail: adil.yucel@itu.edu.tr

2 Prof. Dr., Istanbul Technical University, Mechanical Engineering Dept., Gumussuyu Istanbul Turkey, Tel: +902122931300 (Ext: 2415), e-mail: arpacial@itu.edu.tr
} 


\section{INTRODUCTION}

Platforms are crane-like machines which lift the workers with their equipments to desired height and distance. The word platform was used only for static structures like bridges and ladders till the end of the second half of the $20^{\text {th }}$ century. But in the recent 30 years the platforms are named in different types as follows:

- Jointed Platforms

- Trussed Platform

- Load Platforms

- Telescopic Platforms

- Vertical Platforms

In this study, we have examined the vibrations of telescopic platforms which are widely used in construction areas, airports and harbours. Telescopic platforms are such structures which have at least two long beams sliding in each other called boom. Usually the second boom works with hydraulic cylinders and the other booms work by means of chains. An example of a telescopic platform with 5 booms is shown in Fig. 1.

As the result of the literature survey it has been found that many studies have been implemented using finite element method and three dimensional modelling. Dayawansa et al. [1] describes the cracks which grow in the weld joints (called clusters) and the system by which the booms are protected from catastrophic collapse and the maintenance and repair techniques used to keep them in service. Karahan [2] has designed and analyzed two level telescopic crane by finite element method. The parts of crane have been designed as original and 3D in Pro ENGINEER software. Sheet thickness for main element stationary boom carrying load has been determined by performing stress analysis in ANSYS workbench with finite element method. Marjamaki et al. [3] have extended an idea of the modelling flexible telescopic boom using a non-linear finite element method to the three dimensional case. The boom is assembled by Reissner's geometrically exact beam elements. The sliding boom parts are coupled together by the element, where a slide-spring is coupled to beam with the aid of a master-slave technique. A special element with a revolute joint and an element with offset are developed. Telescopic movement is achieved by the element with varying length and the connector expressing the chains. Ozkan [4] has analyzed connection points of frame crane and investigated stress disributions of connection point components.

The commercial finite element package ANSYS was used for finite element analysis. The main purposes of the paper of Rusiński et al. [5] are to discuss designing problems of machines used in underground mining and investigation of its reasons based on cracked boom of underground mine machine. Numerical and experimental approach was considered. The finite element method was used for numerical simulation. Fractographic and microscopic evaluation, chemical analysis, hardness tests were used to perform material evaluations. The objectives are achieved by numerical simulation of cracked loader boom, material evaluations of specimens and comparison of results achieved from both approaches. These were determined through a numerical experiment, based on a discrete model of the jib boom and predefined boundary conditions. The finite element analysis for the jib boom provided 
information about stress distribution for extreme load conditions. The study included macroscopic and fractographic inspection, microscopic evaluation as well as hardness tests of the material used for the jib boom. Static finite element analysis and weight optimization of the box girder, which constitutes about $50 \%$ of the total weight of gantry crane structures, was computed in the study of Erdol [6]. In this study, vibrational analyses of telescopic platforms have been conducted and these structures have been optimized in order to satisfy vibrational standards.

\section{MODELS}

In this study, a telescopic platform with maximum operation height of $24 \mathrm{~m}$. and having 5 booms has been selected for modelling. The selected telescopic platform to model is shown in Fig. 2.

All the components of the platform have been modelled using Pro/ENGINEER software. The whole model consists of the main parts called foundation, tower, booms, basket joint and basket. The first part modelled is the foundation. The foundation shown in Fig. 3 is based on a $4920 \times 2100 \mathrm{~mm}$ area and the profiles with cross-section of $80 \times 160 \times 6 \mathrm{~mm}$ were used for modelling.

The tower is mounted on the foundation using a group of gears which is located on the reduction gear box. The next part modelled is called the tower shown in Fig. 4.

The base flange of the tower has a thickness of $20 \mathrm{~mm}$. It consists of $16 \times \varnothing 17 \mathrm{~mm}$ holes to mount the gear box. The tower can rotate around its axis 3600 but its operation angle is limited to 1800 . The piston has also been modelled which connects the first boom to the tower shown in Fig. 5.

The properties and images of 5 booms modelled in this study have been given as a table in Table 1.

Table 1. The properties of the booms.

\begin{tabular}{|c|c|c|c|}
\hline $\begin{array}{c}\text { Boom } \\
\text { No. }\end{array}$ & $\begin{array}{c}\text { Length } \\
(\mathbf{m m})\end{array}$ & $\begin{array}{c}\text { Cross- } \\
\text { Section } \\
(\mathbf{m m})\end{array}$ & Model \\
\hline 1 & 4580 & $292 \times 510 \times 8$ & Fig. 6 \\
\hline 2 & 4600 & $250 \times 422 \times 6$ & Fig. 7 \\
\hline 3 & 4630 & $210 \times 340 \times 5$ & Fig. 8 \\
\hline 4 & 4660 & $170 \times 260 \times 5$ & Fig. 9 \\
\hline 5 & 4750 & $132 \times 202 \times 5$ & Fig. 10 \\
\hline
\end{tabular}

One of the most important components of the model is the basket joint shown in Fig. 11. Basket joint is the vital part which connects last boom tho the basket in which the worker operates. The picture of connection is given in Fig. 12. 
The connection wholes 1, 2 and 3 shown in figure are for boom connection, basket connection and balancing piston, respectively.

The last component of the whole model is the basket where the work operates. It has been modelled using $\varnothing 30 \times 2.5 \mathrm{~mm}$ round profiles. It has a base area of $900 \times 1500$ $\mathrm{mm}$ and has a height of $1120 \mathrm{~mm}$. The model of the basket is shown in Fig. 13.

The whole assembled model can be seen in Fig. 14. which is ready to be analyzed.

\section{FINITE ELEMENT ANALYSIS}

After the whole assembled 3D solid model of the telescopic platform obtained, it has been imported to commercial finite element analysis software called ABAQUS for natural frequency and mode shape analyses. The approximate mesh size for the finite element model is $100 \mathrm{~mm}$. The meshed finite element model is shown in Fig. 15. The material properties were taken as,
Density
Poisson Ratio
$: 7850 \mathrm{~kg} / \mathrm{m}^{3}$
Modulus of Elasticity
$: 0,3$
$: 210000 \mathrm{MPa}$

The first 16 natural frequencies are given in Table 2 and first 5 mode shapes are given in Fig. 16.

Table 2. First 16 natural frequencies.

\begin{tabular}{|c|c|c|c|}
\hline Mode No. & $\begin{array}{c}\text { Natural } \\
\text { Frequency (Hz) }\end{array}$ & Mode No. & $\begin{array}{c}\text { Natural } \\
\text { Frequency (Hz) }\end{array}$ \\
\hline 01 & 0,16 & 09 & 12,36 \\
\hline 02 & 0,23 & 10 & 19,59 \\
\hline 03 & 3,16 & 11 & 26,28 \\
\hline 04 & 3,19 & 12 & 30,35 \\
\hline 05 & 3,49 & 13 & 40,15 \\
\hline 06 & 6,44 & 14 & 40,67 \\
\hline 07 & 7,27 & 15 & 49,28 \\
\hline 08 & 10,45 & 16 & 54,81 \\
\hline
\end{tabular}

The operating (exciting) frequency of the system is $12.875 \mathrm{~Hz}$. When we look at Table 2, we can see that there is a natural frequency value $f=12.361 \mathrm{~Hz}$ which is very close to the operating (exciting) frequency of the system. This reveals a danger of resonance in operating conditions. Therefore an optimization process should be conducted on the model. 


\section{EXPERIMENTAL MODAL ANALYSIS}

In order to conduct a forced vibration analysis using finite element method, we needed to know the excitation force of the system. Because of the restrictions of the construction of the telescopic platform, it was impossible to locate a force transducer to measure the force exciting the system. Instead, we measured the acceleration values on the foundation and basket. Then we conducted series of forced vibration analyses using finite element method to satisfy these acceleration values of certain points on which we measured using sensors on the platform. This way, we obtained the excitation force value to use in further optimized structure. The positions of sensors located on the system are shown in Fig. 17.

The spectrum analyses of the acceleration data obtained by the sensors on foundation and basket are shown in Figs. 18-23.

By means of the results of the spectrum analyses, the list of acceleration values at operating frequency is given in Table 3.

Table 3. Acceleration values at operating frequency.

\begin{tabular}{|c|c|c|}
\hline Direction & $\begin{array}{c}\text { Foundation } \\
\left(\mathbf{m m} / \mathbf{s}^{\mathbf{2}}\right)\end{array}$ & $\begin{array}{c}\text { Basket } \\
\left(\mathbf{m m} / \mathbf{s}^{\mathbf{2}}\right)\end{array}$ \\
\hline $\mathrm{x}$ & 5,004 & 9,173 \\
\hline $\mathrm{y}$ & 24,455 & 5,494 \\
\hline $\mathrm{z}$ & 2,203 & 19,532 \\
\hline
\end{tabular}

After the series of forced vibration analyses using finite element method to satisfy these acceleration values done on the model, the exciting distributed force has been obtained to be $8,52 \times 10^{-6}$ tons $/ \mathrm{mm}^{2}$. This force will be used for the analysis of the optimized model.

\section{OPTIMIZATION}

After the finite element and experimental modal analyses we have seen that it is necessary to make an optimization on the platform model. It is clear that there is no need to make any optimization on the foundation and tower. The only parts which need to be optimized are the booms. As the optimization process, we changed the rectangular cross-sections of the booms into rounded cross-sections. The new crosssectional properties of the booms are given in Table 4 and the 3D models are shown in Figs. 24-28.

The optimized assembly is shown in Fig. 29. The results of the finite element analysis conducted on the optimized model is given in Table 5.

It can clearly be seen that there is no natural frequency close the operating (exciting) frequency of the system which is $12.875 \mathrm{~Hz}$. 
Table 4. The properties of optimized booms.

\begin{tabular}{|c|c|c|c|}
\hline $\begin{array}{c}\text { Boom } \\
\text { No. }\end{array}$ & $\begin{array}{c}\text { Length } \\
(\mathbf{m m})\end{array}$ & $\begin{array}{c}\text { Cross- } \\
\text { Section } \\
(\mathbf{m m})\end{array}$ & Optimized Model \\
\hline 1 & 4580 & $\varnothing 340 \times 12$ & Fig. 24 \\
\hline 2 & 4750 & $\varnothing 280 \times 12$ & Fig. 25 \\
\hline 3 & 4754 & $\varnothing 232 \times 10$ & Fig. 26 \\
\hline 4 & 4752 & $\varnothing 184 \times 8$ & Fig. 27 \\
\hline 5 & 4750 & $\varnothing 132 \times 8$ & Fig. 28 \\
\hline
\end{tabular}

Table 5. First 16 natural frequencies of optimized model.

\begin{tabular}{|c|c|c|c|}
\hline Mode No. & $\begin{array}{c}\text { Natural } \\
\text { Frequency (Hz) }\end{array}$ & Mode No. & $\begin{array}{c}\text { Natural } \\
\text { Frequency (Hz) }\end{array}$ \\
\hline 01 & $7,74 \mathrm{E}-02$ & 09 & 5,38 \\
\hline 02 & $8,34 \mathrm{E}-02$ & 10 & 9,62 \\
\hline 03 & 1,14 & 11 & 10,82 \\
\hline 04 & 1,15 & 12 & 17,73 \\
\hline 05 & 1,99 & 13 & 17,96 \\
\hline 06 & 2,30 & 14 & 18,89 \\
\hline 07 & 2,44 & 15 & 23,67 \\
\hline 08 & 4,17 & 16 & 29,09 \\
\hline
\end{tabular}

\section{CONCLUSION}

Although it was impossible to locate a force transducer into system and to measure the acting force, the distributed force has been obtained to be $8,52 \times 10^{-6}$ tons $/ \mathrm{mm}^{2}$ by taking the acceleration values obtained experimentally into account. This force value can be used in any modal analysis on this model.

The operating (exciting) frequency of the system is $12.875 \mathrm{~Hz}$. When we look at the table of natural frequencies of the original model, we can see that there is a natural frequency value $12.361 \mathrm{~Hz}$ which is very close to the operating (exciting) frequency of the system. This reveals a danger of resonance in operating conditions. After the optimization, it can clearly be seen that there is no natural frequency close the operating (exciting) frequency of the system. This states the importance of the optimization.

As we examined the related standard, it can be seen that the acceleration values on the basket were very high for workers. After the optimization we have obtained a serious reduction on acceleration values. The acceleration values on the basket before and after the optimization are given in Table 6. 
Table 6. Comparion of acceleration values on the basket.

\begin{tabular}{|c|c|}
\hline Before optimization & $1,384 \mathrm{~mm} / \mathrm{s}^{2}$ \\
\hline After optimization & $0,1894 \mathrm{~mm} / \mathrm{s}^{2}$ \\
\hline
\end{tabular}

\section{REFERENCES}

[1] Dayawansa, P., Chitty, G., Kerezsi, B., Bartosiewicz, H. and Price, J.W.H., "Fracture Mechanics of Mining Dragline Booms", SIF2004 Structural Integrity and Fracture, (2005).

[2] Karahan, M., "Design and Finite Element Analysis of Two Levels Telescopic Crane", (in Turkish), Erzurum Ataturk University, Unpublished MA Thesis, (2007).

[3] Marjamaki H. and Makinen J., "Modelling a telescopic boom - the 3D case: Part II", Computers and Structers, No: 84, pp 2001-2002, (2006).

[4] Ozkan, I., "Computer Aided Design and Analysis of Frame Crane", Izmir Dokuz Eylul University, Graduate School of Natural and Applied Sciences, Unpublished MA Thesis, (2005).

[5] Rusiński, E., Czmochowski, J. and Moczko, P., "Numerical and Experimental Analysis of a Mine's Loader Boomcrack", Journal of Achievements in Materials and Manufacturing Engineering", Vol. 17, Issue. 1-2, pp 273-276, (2006).

[6] Erdol, T., "Design, Analysis of The Gantry Crane with Finite Element Method and Box Girder Optimization", (in Turkish), Gebze Institute of Technology, Unpublished MA Thesis, (2007). 


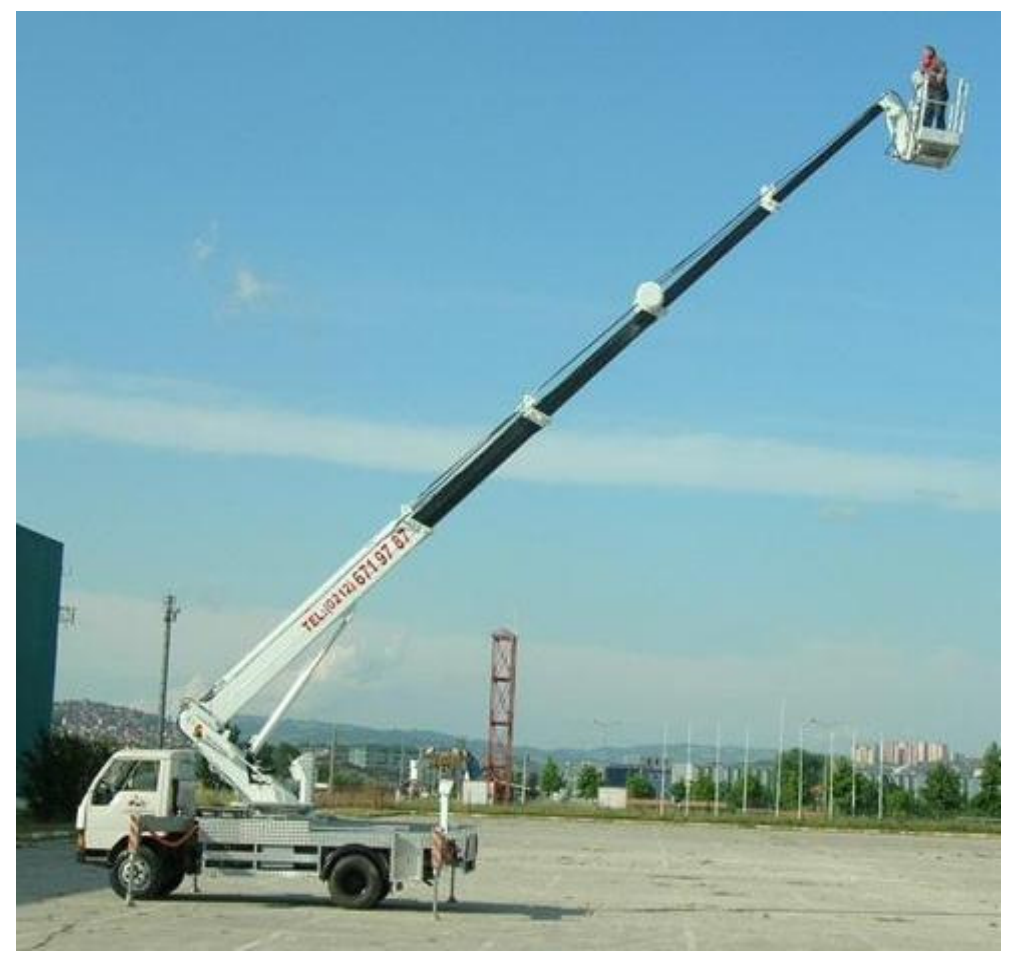

Fig. 1. An example of 5 boom telescopic platform.

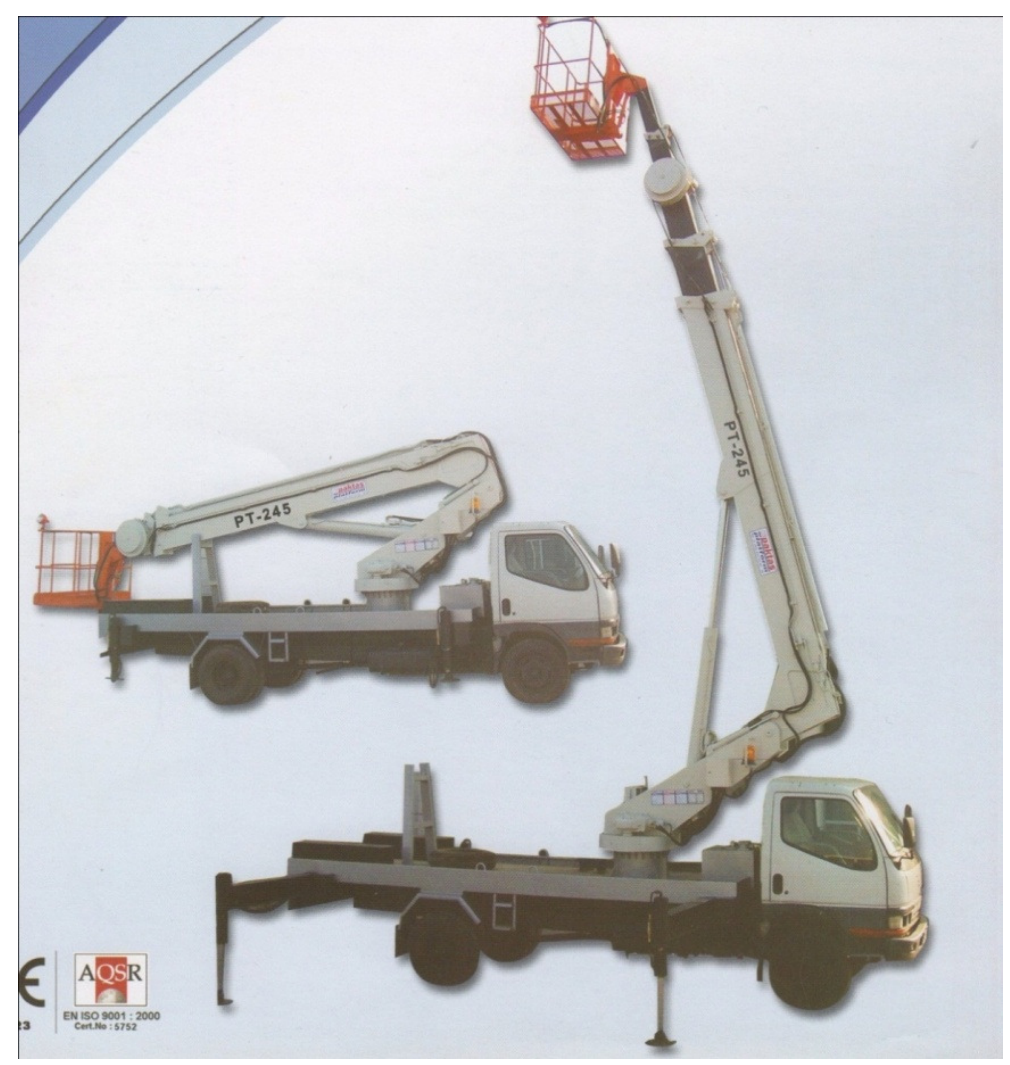

Fig. 2. The telescopic platform selected for modelling. 


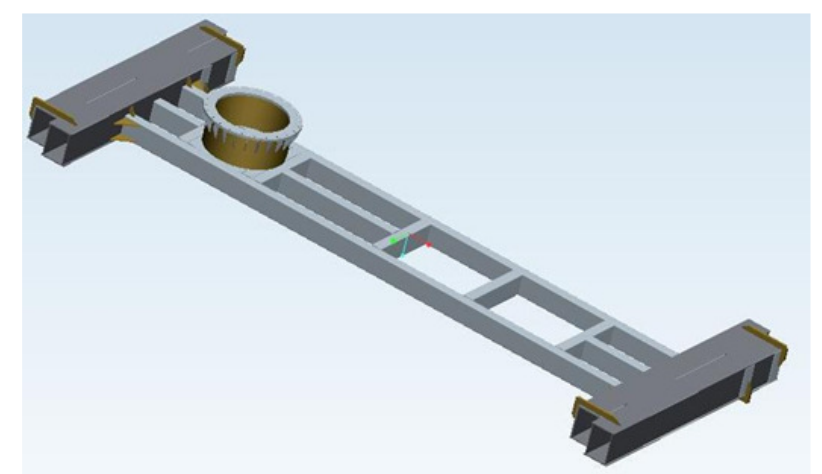

Fig. 3. The foundation.

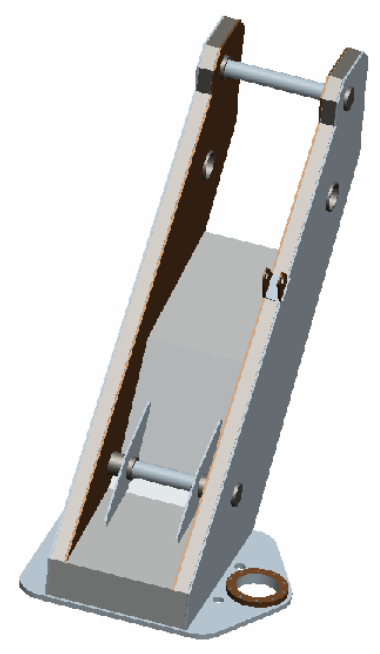

Fig. 4. The tower.

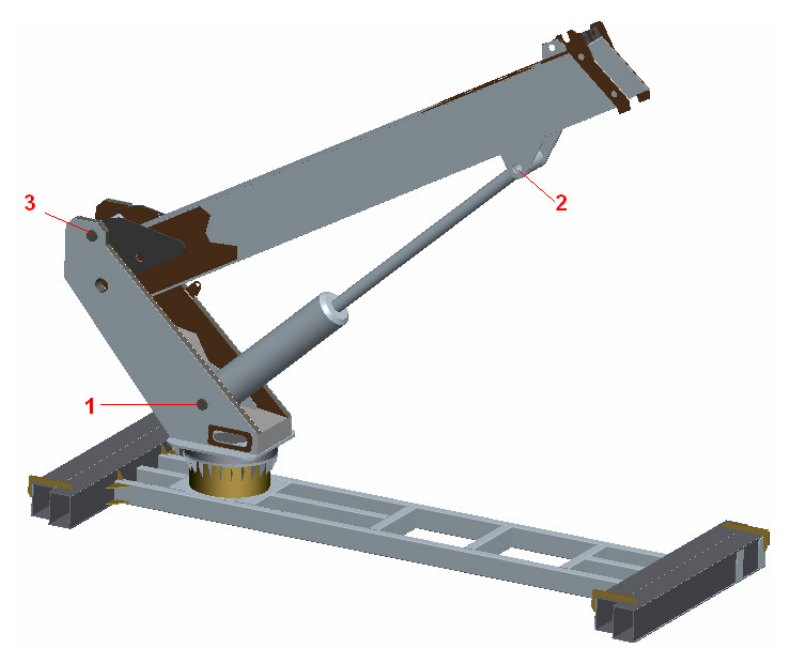

Fig. 5. Piston connection. 


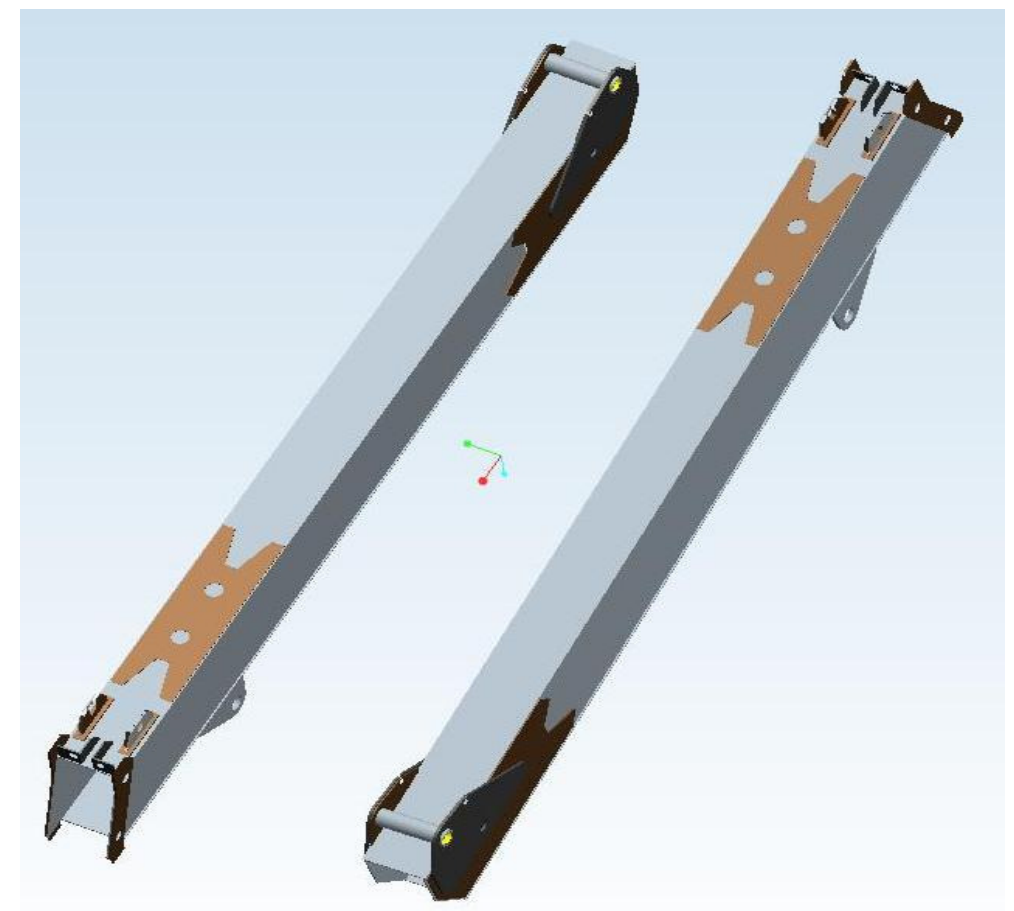

Fig. 6. Boom 1.

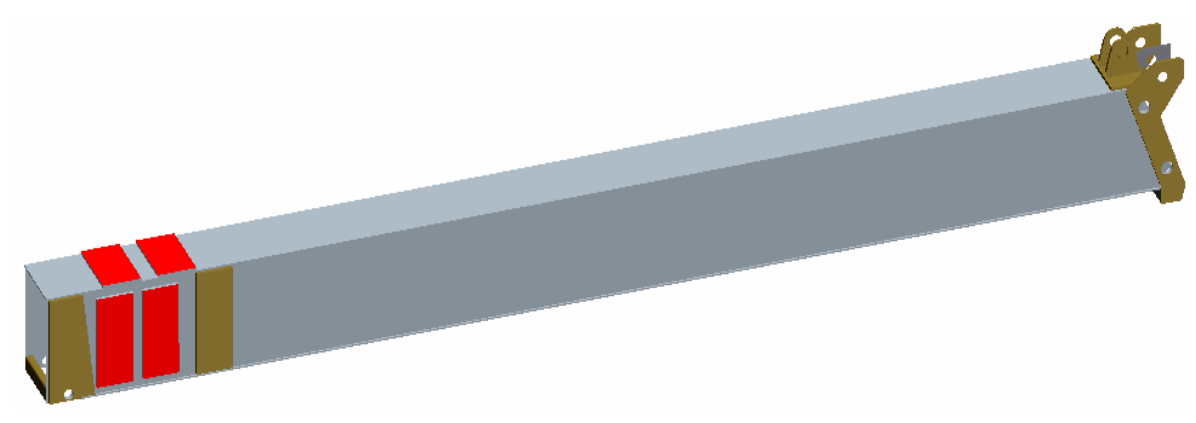

Fig. 7. Boom 2.

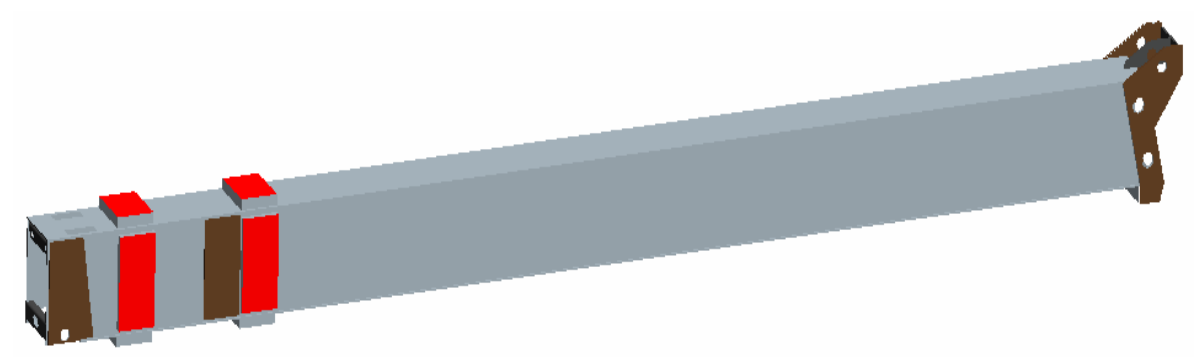

Fig. 8. Boom 3. 


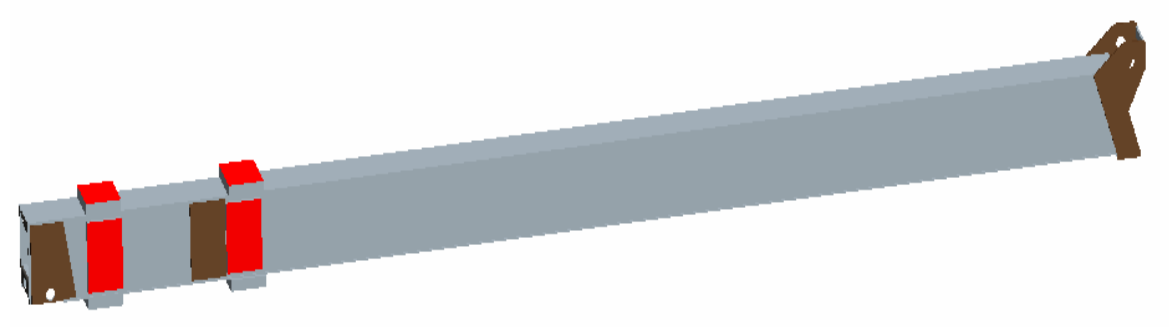

Fig. 9. Boom 4.

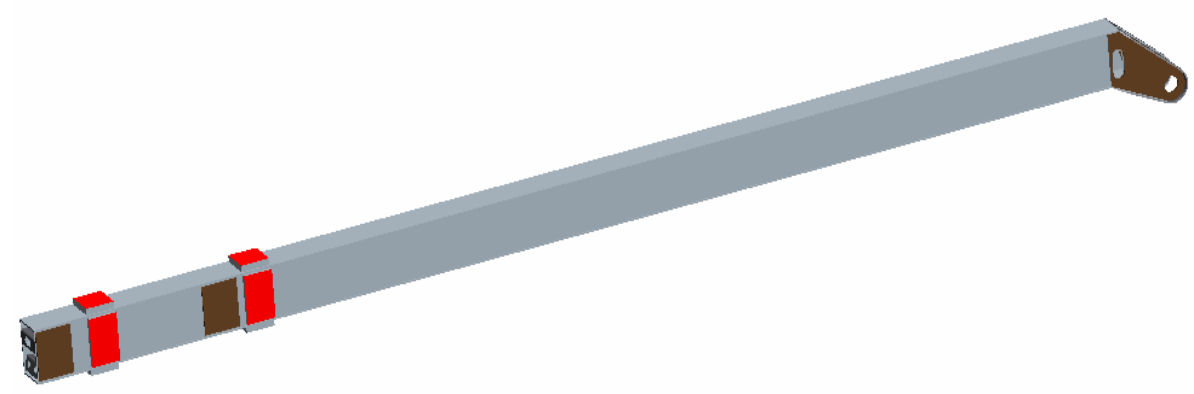

Fig. 10. Boom 5.

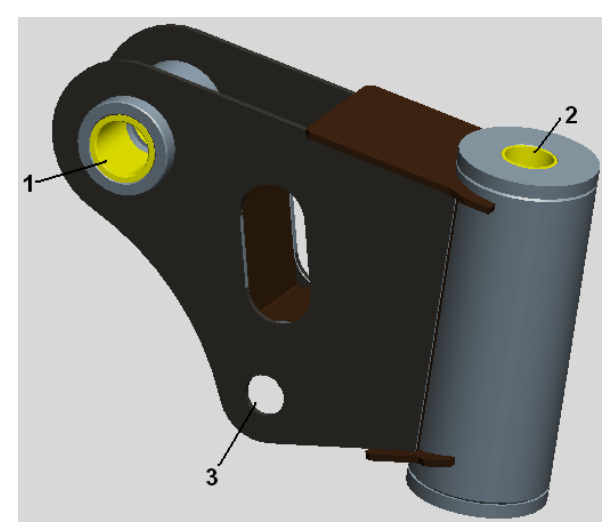

Fig. 11. Basket joint.

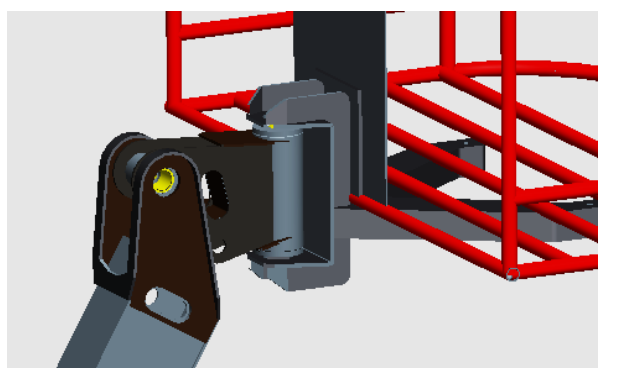

Fig. 12. Connection of boom and basket. 


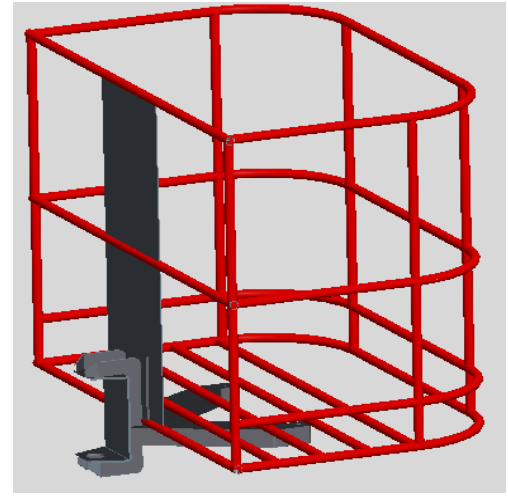

Fig. 13. The basket.

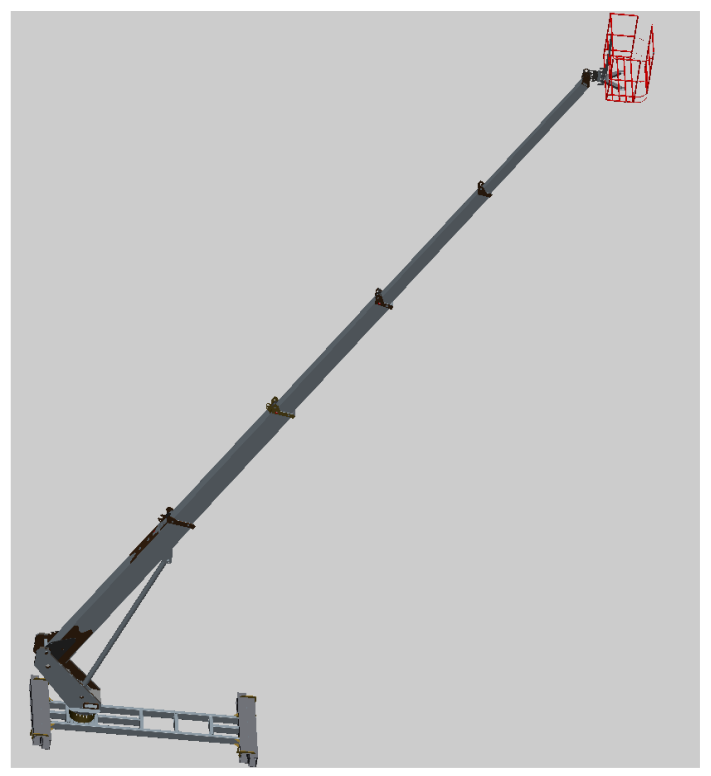

Fig. 14. The assembly.

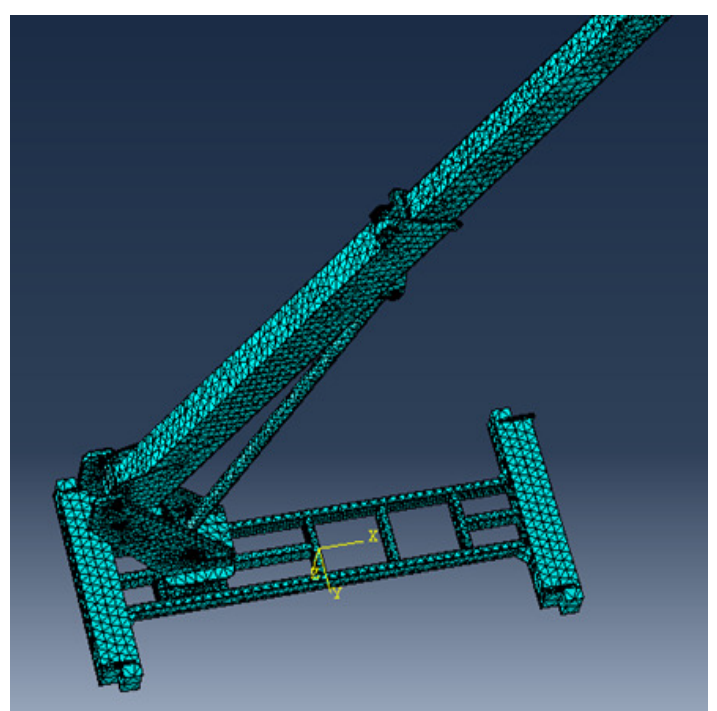

Fig. 15. Finite element model. 


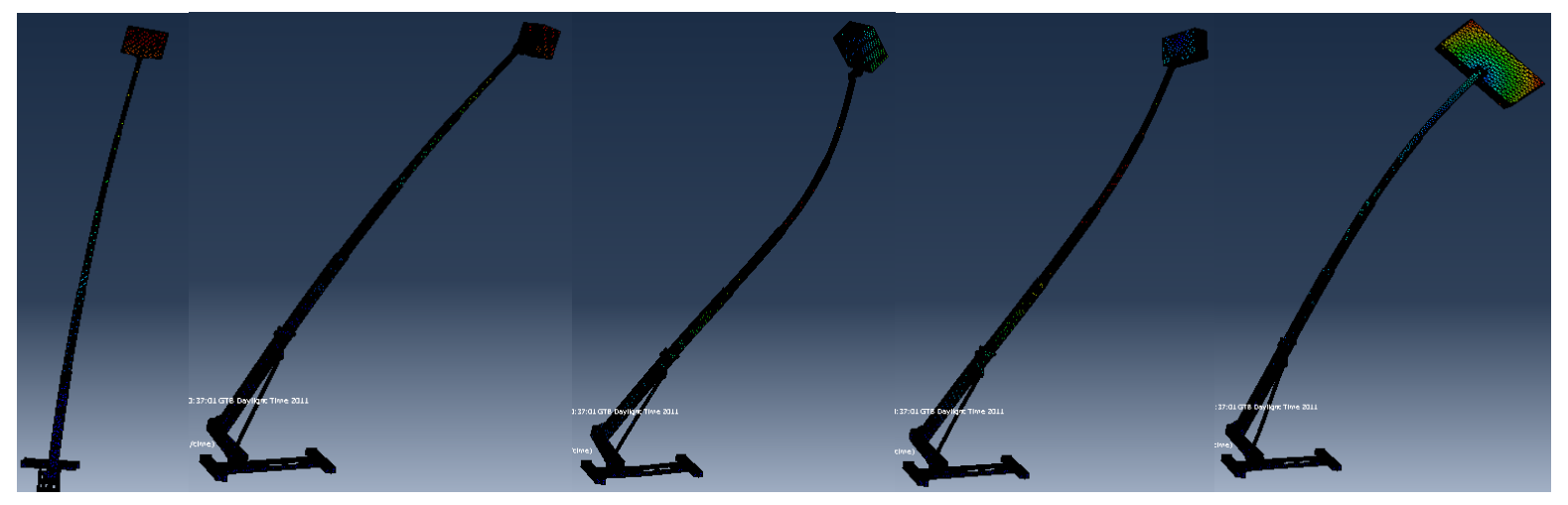

Fig. 16. Mode shapes.

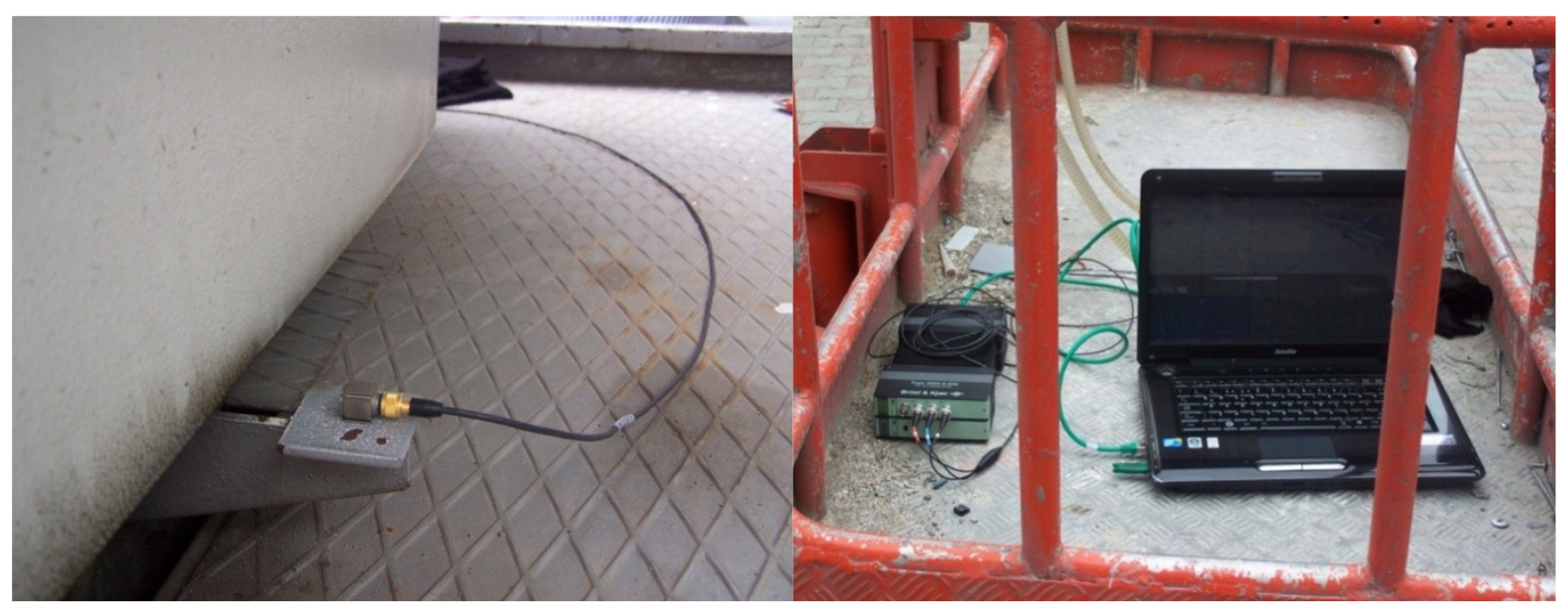

Fig. 17. The locations of the sensors on foundation and basket.

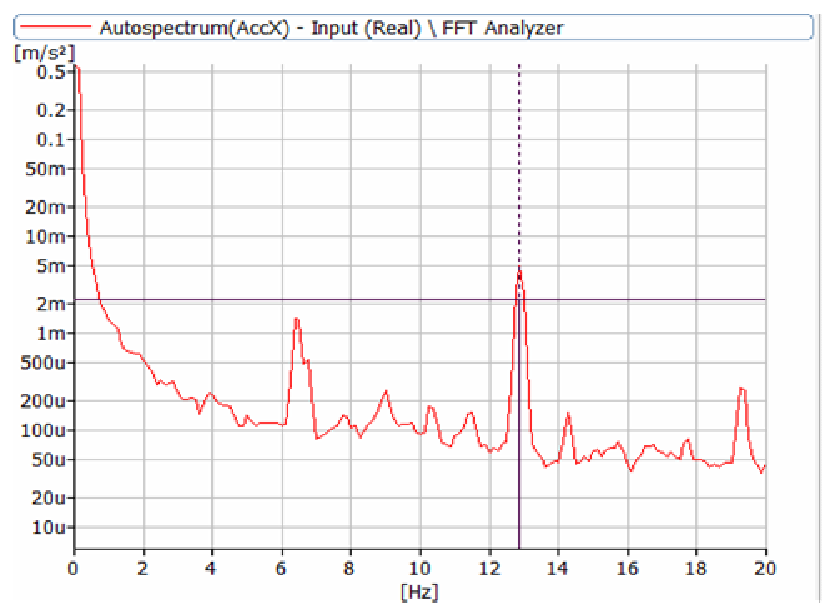

Fig. 18. Spectrum analysis of foundation in $x$ direction. 


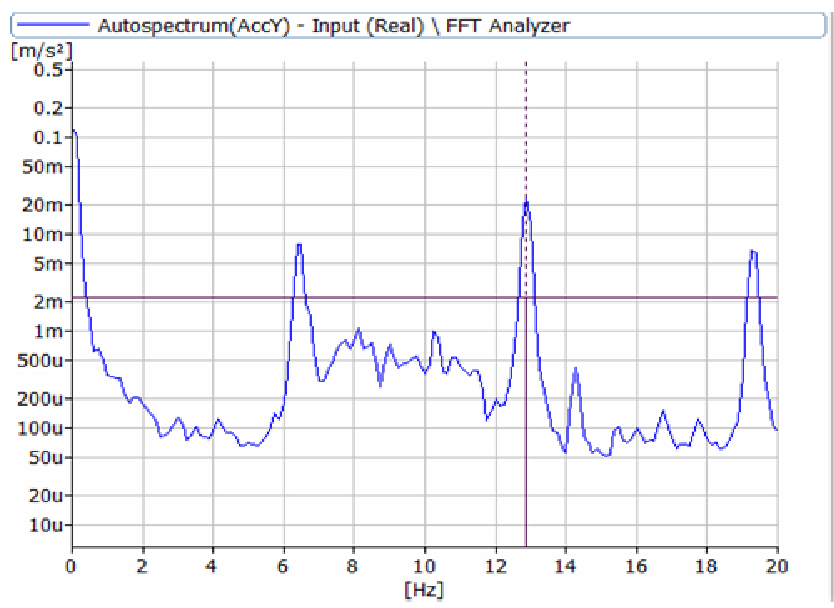

Fig. 19. Spectrum analysis of foundation in y direction.

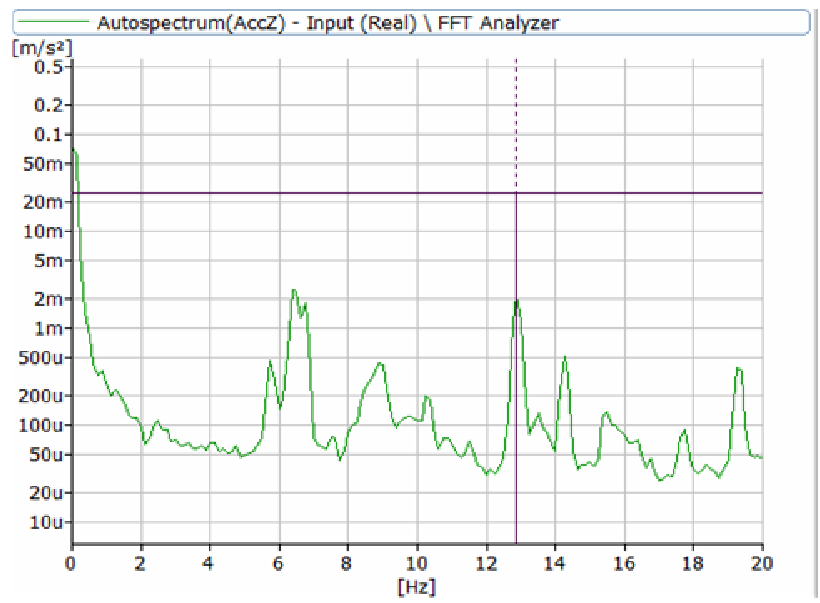

Fig. 20. Spectrum analysis of foundation in z direction.

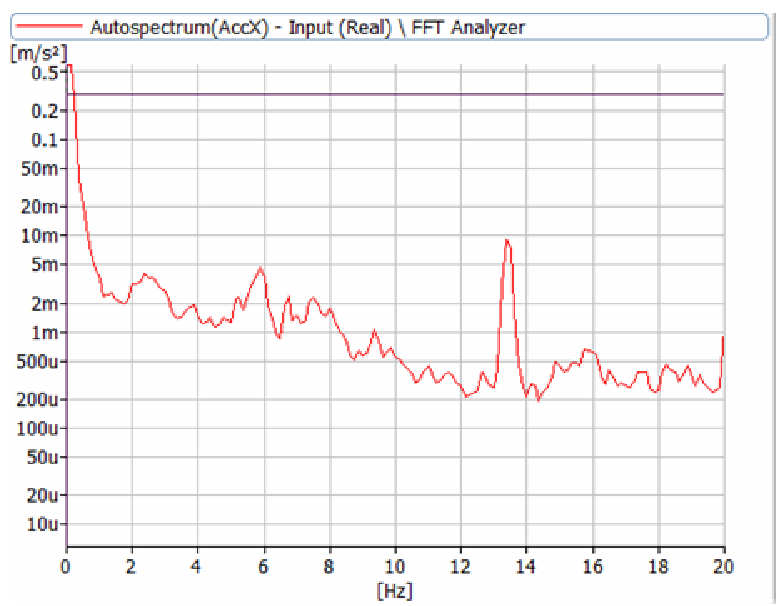

Fig. 21. Spectrum analysis of basket in $\mathrm{x}$ direction. 


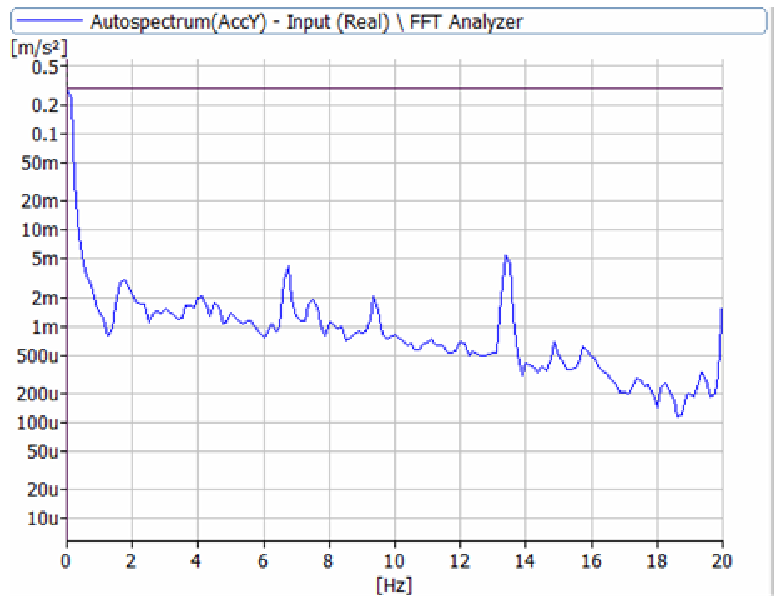

Fig. 22. Spectrum analysis of basket in y direction.

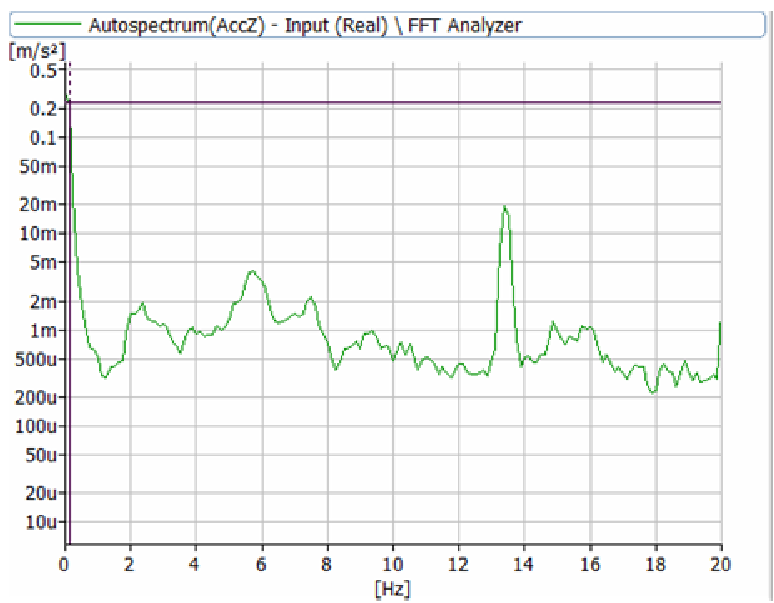

Fig. 23. Spectrum analysis of basket in z direction.

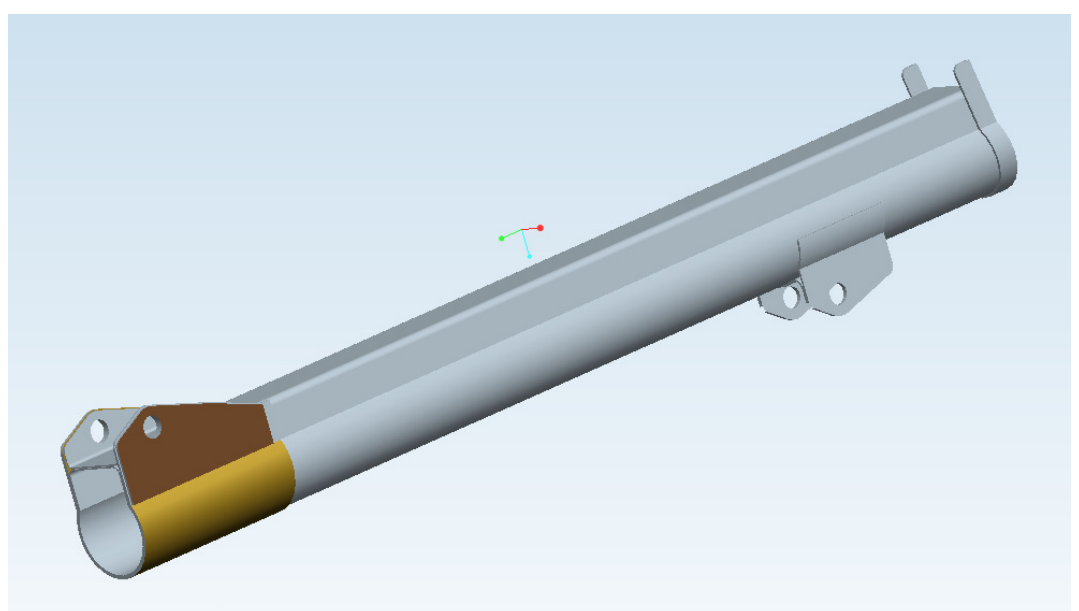

Fig. 24. Optimized boom 1. 


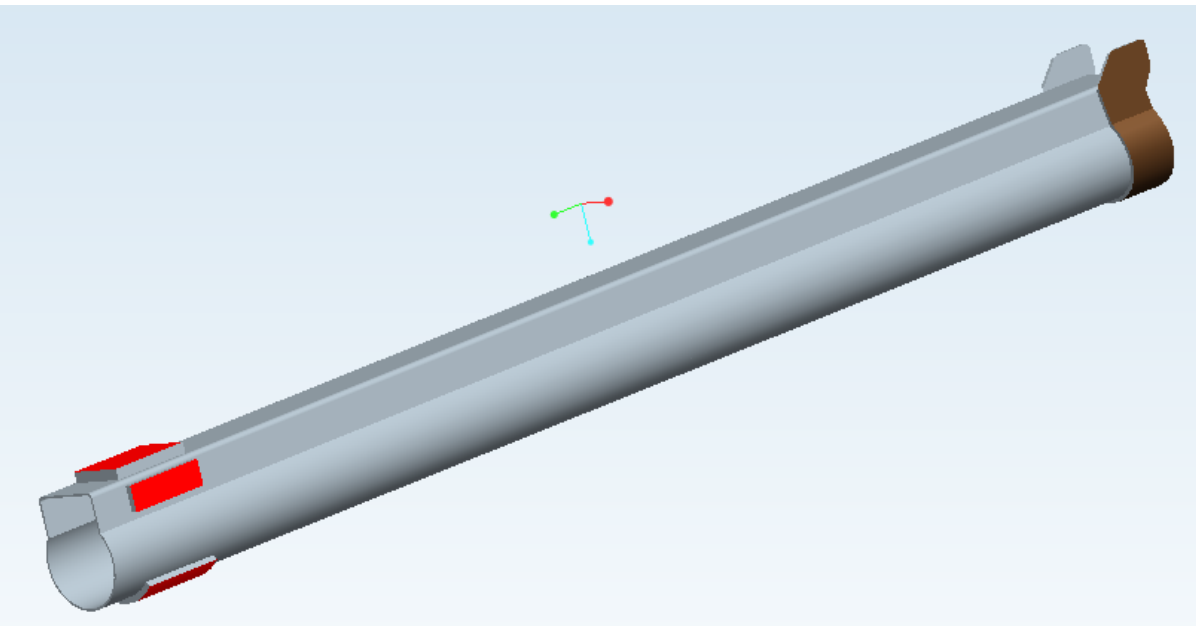

Fig. 25. Optimized boom 2.

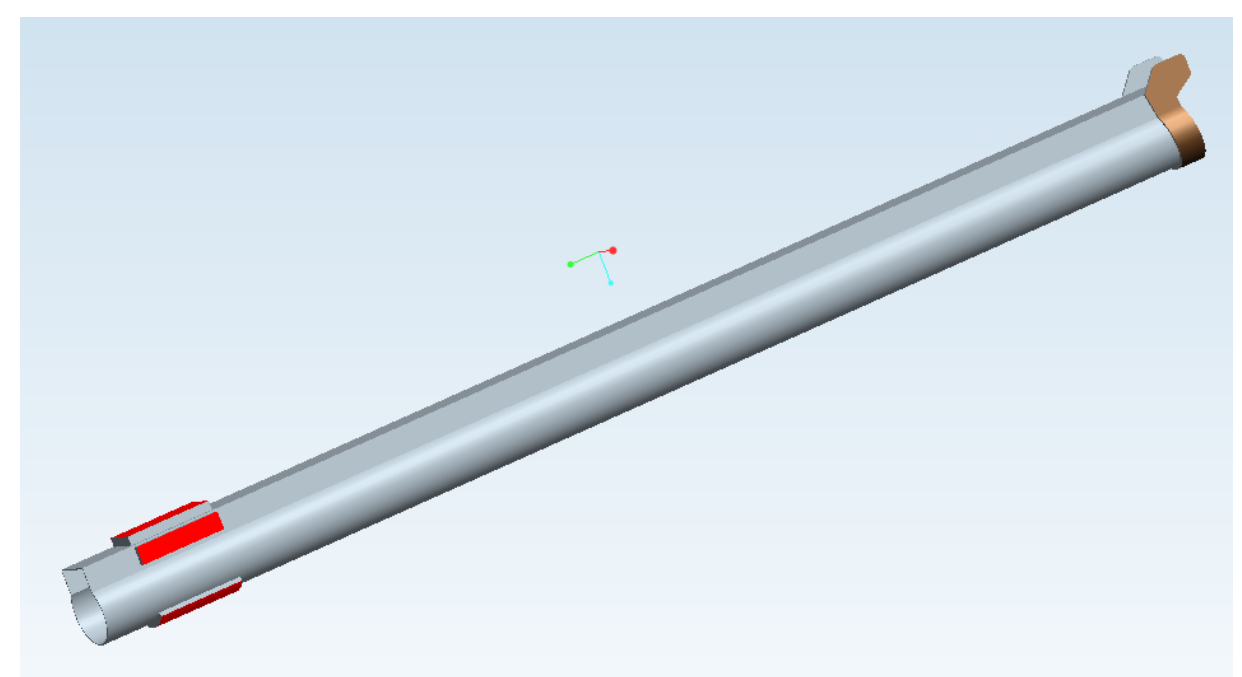

Fig. 26. Optimized boom 3.

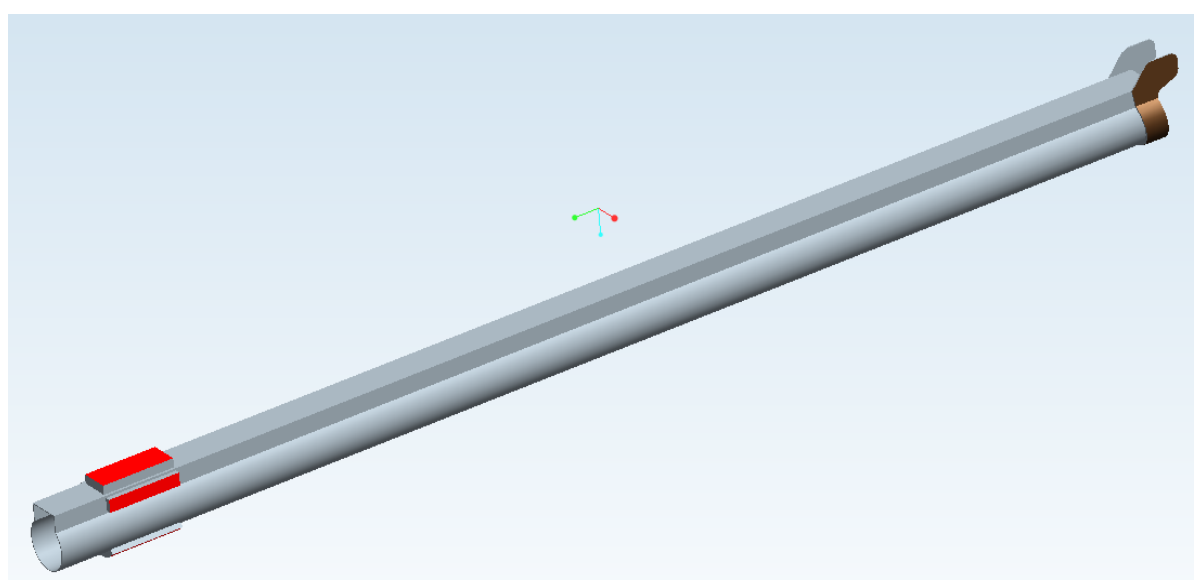

Fig. 27. Optimized boom 4. 


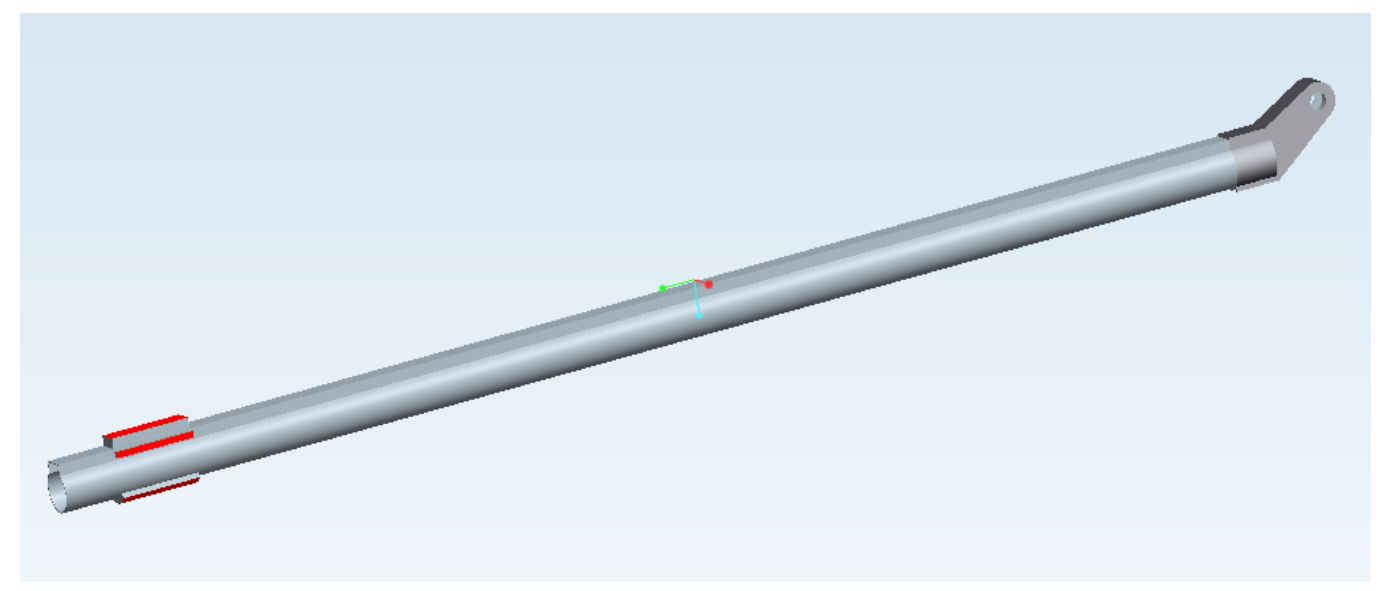

Fig. 28. Optimized boom 5.

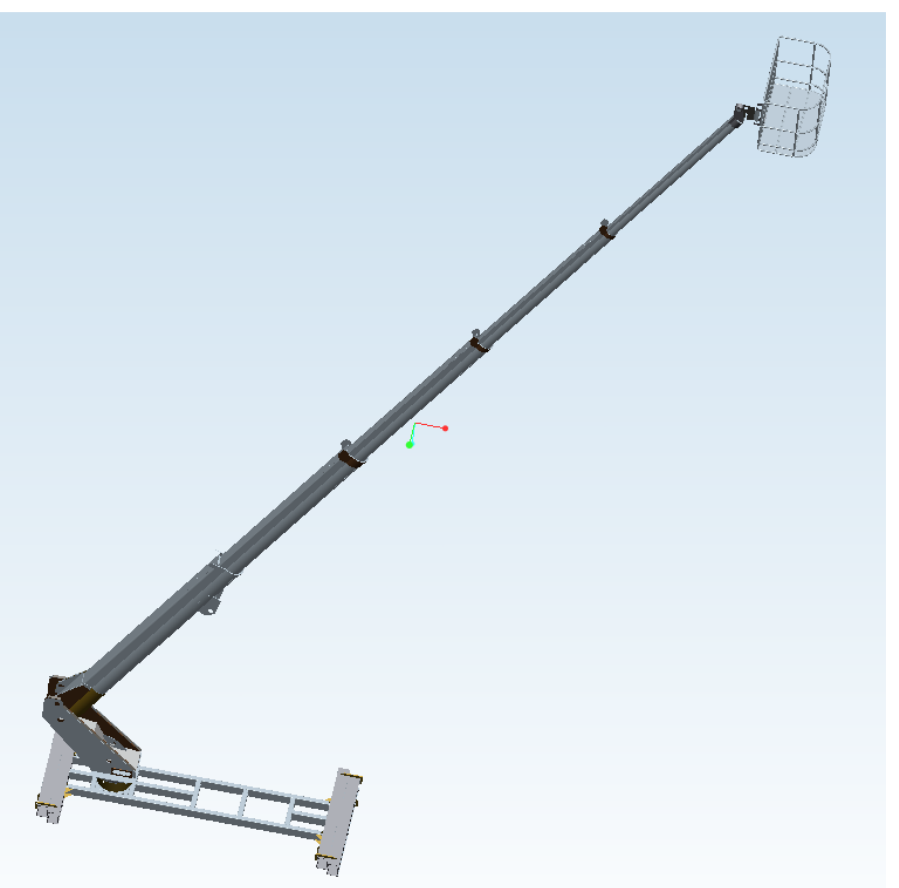

Fig. 29. Optimized assembly. 